\title{
STRUCTURAL STABILITY OF CUBE AND ROCK-ARMOURED SUBMERGED BREAKWATERS FOR BEACH PROTECTION
}

\author{
José F. Sánchez-González', Joaquín Garrido Checa²; Mª Dolores Ortiz Sánchez ${ }^{3}$ and Manuel \\ Martín Huescar ${ }^{1}$
}

\begin{abstract}
This paper presents the results from a new set of 3-D physical model tests performed in a $6.5 \mathrm{~m}$ wide flume at the Centre for Harbour and Coastal Studies in Madrid. These results will contribute to enhance the existing knowledge obtained in previous studies. Among other variables, they cover concrete-cubes armours and the submergence is increased, with a higher model scale. Damage criterions are discussed and proposed for both types of armour. The latter takes into account the different damage growth observed between rock and cubes-armours. Lower thresholds are proposed for cubes in order to increase the safety, though still allowing some movements before considering the damage is reached.
\end{abstract}

Keywords: submerged; rubble-mound breakwater; rock armour; concrete cubes; armour stability; damage

\section{INTRODUCTION}

Coastline stability in unbalanced beaches or new coastal developments is usually associated to protection works that aim at reducing the wave energy on the coast. These structures must induce processes of wave attenuation during storm situations while preserving the best environmental conditions, including water and landscape quality. In order to fulfil both types of requirements lowcrested (LCS) or submerged detached breakwaters are generally considered one of the first alternatives to be studied.

During the last two decades several researches have dealt with the stability and hydraulic performance of conventional multi-layered LCS. Regarding the stability, these previous works were based mainly on experimentation of physical models where few variables were considered in addition to the wave height and non-dimensional freeboard. van der Meer (1988) tested a 2-D model of a $D_{\mathrm{n} 50}=$ $3.44 \mathrm{~cm}$ rock-armoured rubble-mound breakwater with slopes $2 / 1$ at the seaside and $3 / 2$ at the leeside, including the study of the wave steepness effect in the stability. Taking into account his own experiments and those carried out by Ahrens (1989) and Givler and Sørensen (1986), van der Meer (1994) proposed a design method for submerged breakwaters. Vidal et al. (1992) tested a 3-D model of a $2.5 \mathrm{~cm}$ rock-armoured rubble-mound single detached breakwater with slopes $3 / 2$ in order to study the stability of the different regions of the structure. Starting from these results, a new design method is proposed in Vidal et al. (2000). More recently, Kramer and Burcharth (2002) tested a 3-D model of a $3.33 \mathrm{~cm}$ rock-armoured rubble-mound breakwater with slopes $2 / 1$. As in the previous cases, their work included the study of other variables considered secondary as the breaking waves, wave steepness, crest width, obliquity and 3-D waves. From this, Burcharth et al. (2006) set another design formula for initiation of damage. The authors recommended designing for low or no damage, i.e. initiation of damage, given that it is cumulative.

In summary, though many authors have proposed their own design methods, the variety of studies has created a wide database that allows to design according to the most proper research, depending on the tests that best suits the designed structure, wave climate or safety level. Nevertheless, some gaps still have to be covered in order to design in special conditions. In the Canary Islands (Spain) for example, the lack of supplies of rocks greater than 1000 or $2000 \mathrm{~kg}$ has resulted in the use of different armour units such as concrete cubes for their coastal structures. Additionally, their volcanic nature results sometimes a very steep foreshore slope, making it necessary to perch the new beach nourishments with a submerged structure, in order to avoid sediment losses. The present work has taken into account these conditions, including concrete cubes in one of the two models tested and a higher relative submergence, in comparison with previous researches. Finally, the influence of very low wave steepness has also been dealt with.

Regarding the safety level, for beach protection purposes the value of the leeside facilities could be minor. Thus, a greater degree of erosion could be allowed in order to reduce the armour unit size and the total costs of the structure. For two-layer armoured breakwaters, Losada et al. (1986) defined four

\footnotetext{
${ }^{1}$ Centre for Harbour and Coastal Studies, CEDEX, Antonio López 81, Madrid, 28026, Spain

${ }^{2}$ Iberport Consulting, Botiguers 3, Paterna, Valencia, 46980, Spain

${ }^{3}$ Dirección General de Sostenibilidad de la Costa y el Mar, Ministerio de Medio Ambiente y Medio Rural y Marino. Plaza San Juan de la Cruz, Madrid, 28047, Spain
} 
stages of damage, being the first two categories associated to the outer layer. For some specific situations, one of these two categories could be allowed when designing, provided a sufficient safety level and that the damage will not affect to the inner layer.

This work is structures as follows: firstly, the experimental design and model setup are described. The next section deals with the damage, describing its characterization and focusing on the definition of the criterions to identify three different degrees of damage. This could be considered as a main issue, since the final design of the armour layers depends on it. Next, the results will be presented, including the damage description and the stability of the two types of armour units. Conclusions are drawn in the final section.

\section{MODEL SETUP}

\section{Test design and program}

The experiments were carried out in the Laboratory for Maritime Experimentation, at the Centre for Harbour and Coastal Studies of CEDEX, Spain. Two 3-D models were constructed in a wave flume $36 \mathrm{~m}$ long, $6.5 \mathrm{~m}$ wide and $1.3 \mathrm{~m}$ deep (Fig. 1), equipped with a piston type wave generator to produce both regular and random waves, the latter with significant wave heights up to $25 \mathrm{~cm}$. The flume bed was horizontal over the $8 \mathrm{~m}$ long wave generation area, and then a $4 \%$ slope led to a horizontal bottom $11.75 \mathrm{~m}$ long, where the two tested models were built.

Each model represented a $2 \mathrm{~m}$ long and $0.45 \mathrm{~m}$ height detached breakwater perpendicular to the wave incidence direction. Between the models there was a gap $2.5 \mathrm{~m}$ wide, measured at the crest of the breakwater. The models were armoured one with two layers of rocks of nominal size $D_{\mathrm{n} 50}=4 \mathrm{~cm}$ and the other with two layers of precast concrete cubes with $D=4 \mathrm{~cm}$. Other geometrical parameters that were kept constant are slopes (3H/2V) and the crest width and height (see Fig. 2).

This design was set in order to reach the initiation of destruction (Losada et al., 1986) or at least the intermediate damage for the most submerged structure. Wave breaking in front of the structure was avoided so that the wave height was non-depth-limited and the damage growth could be analysed. Though some waves broke for the highest sea states, the fraction of broken waves was always less than $2.5 \%$.
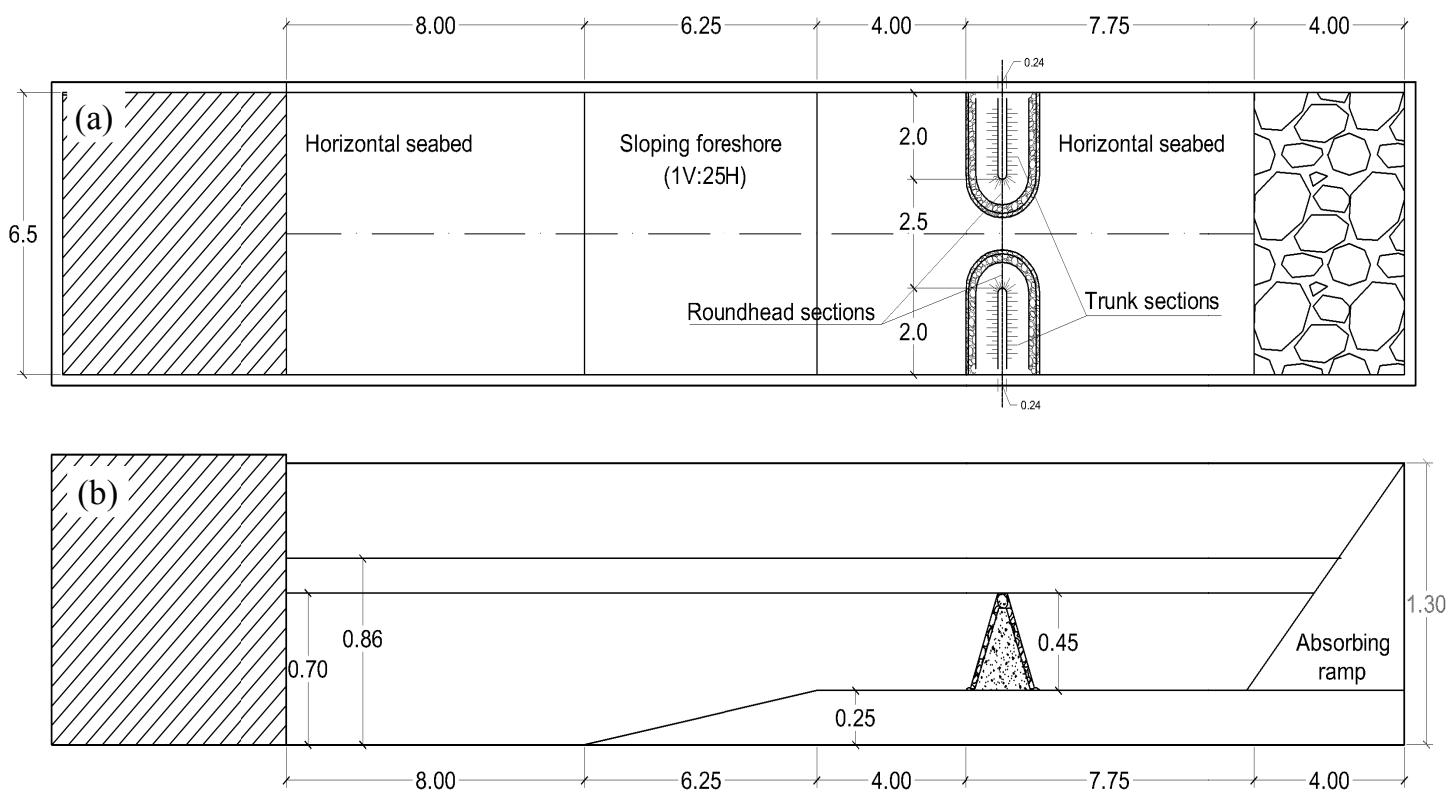

Figure 1. Wave flume layout in Laboratory for Maritime Experimentation, CEDEX. (a) Plan, (b) Longitudinal section; lengths in $(m)$ 


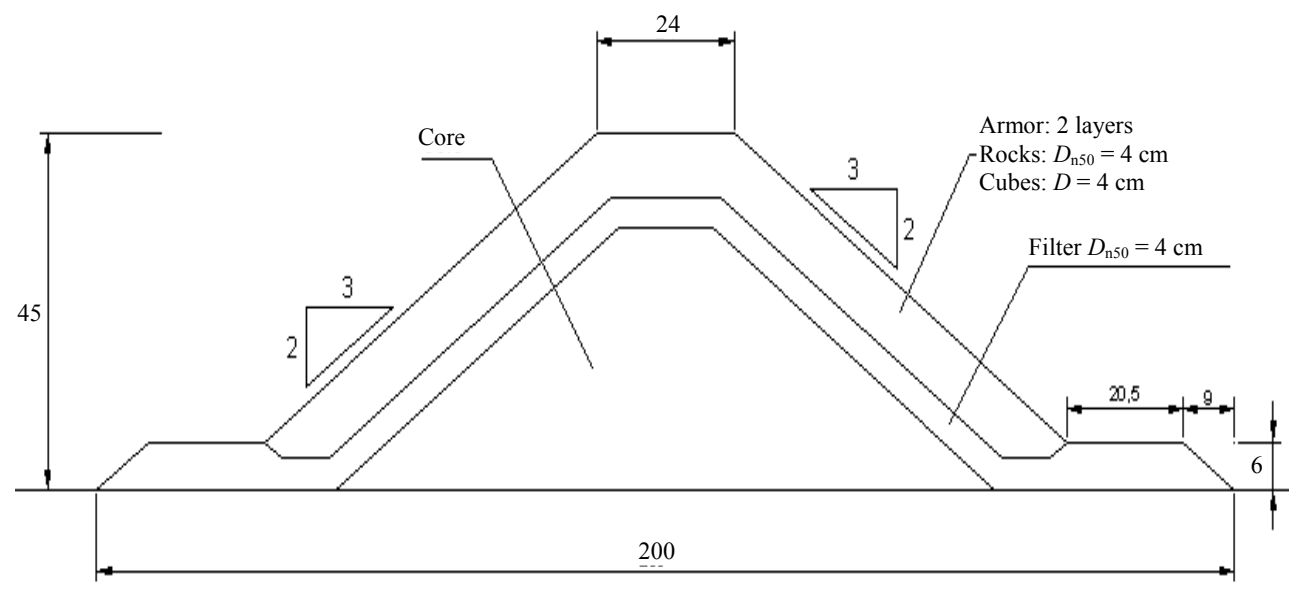

Figure 2. Models cross section. Distances in (cm)

The experimentation consisted of 12 tests (Table 1) obtained from the combination of four different water levels at the toe $\left(h_{\mathrm{t}}\right)$ and three typical wave steepness $\left(s_{0, \mathrm{p}}\right)$. The freeboard $\left(R_{\mathrm{c}}\right)$ ranged from zero to very submerged structures (negative freeboard). The minimum relative freeboard $R_{\mathrm{c}} / D_{\mathrm{n} 50}$ $=-4$ lowers those from previous researches.

Each test consisted of several sea states of random waves with increasing significant wave height, starting from no-damage conditions and lasting until the initiation of destruction or wave breaking conditions were reached. In order to study the damage growth depending on the number of waves, each sea state was divided in 4 runs of 500 waves, resulting in a total of 2000 waves per sea state. All the tests were carried out with random waves with JONSWAP spectrum with $\gamma=3.3$.

\section{Wave measurements}

The free surface elevation was measured using nine wave gauges, three located close to the wave paddle to record the generated waves and the other six in two groups of 3 located in front of both structures in order to measure the wave. Wave reflection at the flume end was minimized by a parabolic beach made of granular material.

Prior to the model construction, wave calibration was carried out in order to ensure the accurate generation of waves during the tests. During this calibration, the reflection coefficient $K_{\mathrm{r}}(\%)$ in the absorbing ramp was evaluated by the method of Mansard and Funke (1980). Results (see Fig. 3) showed values lower than $30 \%$ for most of the cases with $H_{\mathrm{s}} \leq 0.20 \mathrm{~m}$, and a maximum of $K_{\mathrm{r}}=38 \%$ for $H_{\mathrm{s}}=0.22 \mathrm{~m}$ and $s_{0, \mathrm{p}}=0.0175$, being $H_{\mathrm{s}}$ the incident significant wave height (measured at the toe of the structure) and $T_{\mathrm{P}}$ the spectral peak period.

\begin{tabular}{|c|ccc|c|}
\hline \multicolumn{6}{|c|}{ Table 1. Test program } \\
\hline Test & $h_{\mathrm{t}}(\mathrm{m})$ & $R_{\mathrm{c}}(\mathrm{m})$ & $R_{\mathrm{d}} / D_{\mathrm{n} 50}$ & $S_{0, \mathrm{p}}$ \\
\hline 1 & 0.45 & 0 & 0 & \\
2 & 0.51 & -0.06 & -1.5 & \\
3 & 0.57 & -0.12 & -3.0 & 0.0175 \\
4 & 0.61 & -0.16 & -4.0 & \\
\hline 5 & 0.45 & 0 & 0 & \\
6 & 0.51 & -0.06 & -1.5 & \\
7 & 0.57 & -0.12 & -3.0 & 0.025 \\
8 & 0.61 & -0.16 & -4.0 & \\
\hline 9 & 0.45 & 0 & 0 & \\
10 & 0.51 & -0.06 & -1.5 & \multirow{2}{*}{0.035} \\
11 & 0.57 & -0.12 & -3.0 & \\
12 & 0.61 & -0.16 & -4.0 & \\
\hline
\end{tabular}




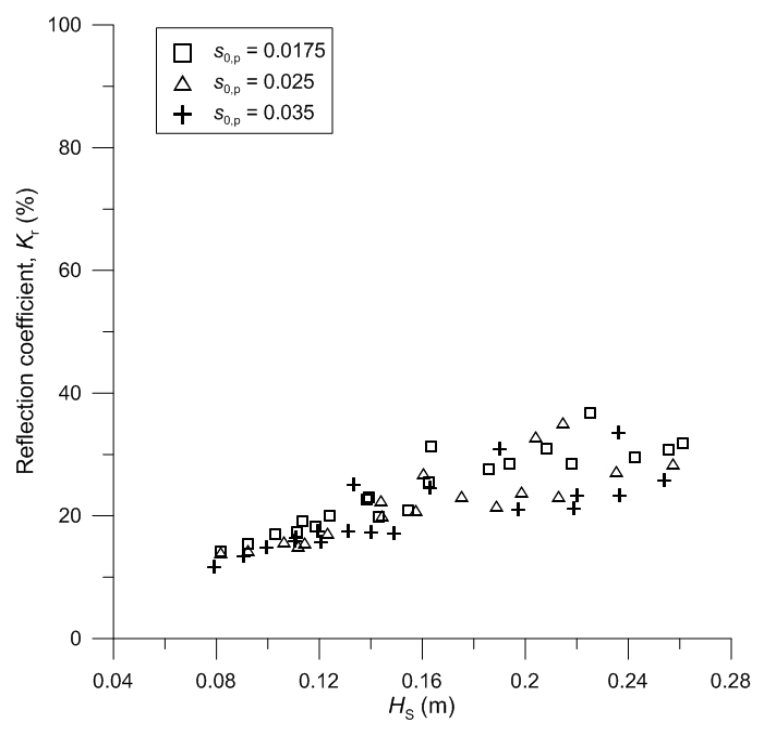

Figure 3. Reflection coefficient measured in front of the absorbing ramp during the wave calibration phase depending on the significant wave height.

\section{DAMAGE CHARACTERIZATION}

\section{Damage measurement}

The damage of the structures was measured counting the number of stones displaced from its original position $\left(N_{\mathrm{d}}\right)$ after every run of 500 waves. The damage was monitored at the crest and the slopes independently and also at the trunk and the head were treated separately. In order to do this, different colours were used for the outer armour units, depending on their position in the breakwater. The inner layer units were coloured in yellow so that the contrast could help to identify each displacement.

Regarding the number of displaced units, only those that contributed to increase the total eroded area were counted (Fig. 4). This means that the units displaced that covered a gap left by other units displaced before were not added so that the number of displacements $N_{\mathrm{d}}$ could be related to the relative eroded area or damage parameter, $S$, used in other previous investigations.

In order to focus in the most significant results, the next section deals only with the stability of the crest, since this is the less stable section. Besides, the results of head and trunk are added, as long as the tests showed that their behaviours were quite similar.

\section{Criterions of damage}

Types of damage. According to Losada et al. (1986) damage can be classified into four qualitative categories depending on the degree of erosion of the armour layers. Prior to this, they considered that there is No Damage when very few armour units are displaced from their original positions and there is no apparent effect in the armour layer.

(1)

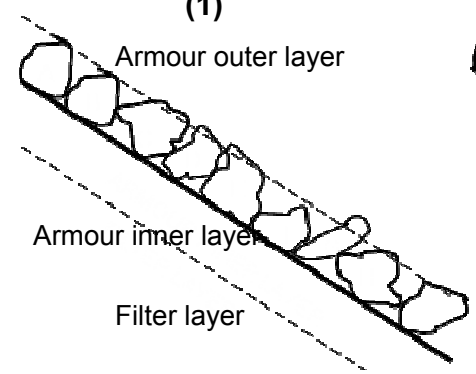

(2)

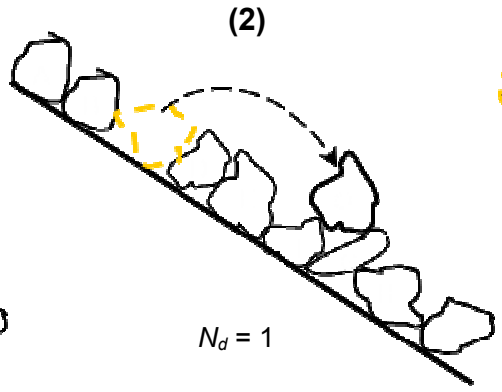

(3)

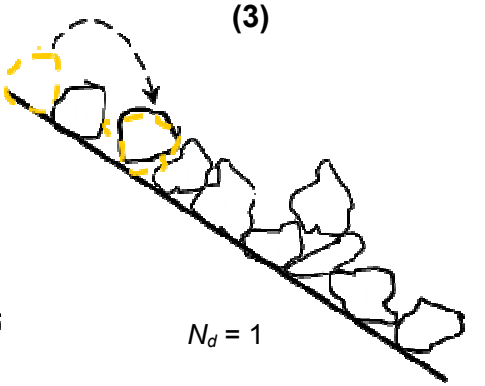

Figure 4. Damage characterization process did not take into account those stones laid in a gap that had been left by other piece displaced before, as shown in images (2) and (3). 
The initiation of damage (IA) starts when more units are displaced from the outer armour layer and there is an increase in the layer porosity, but without any big hole on it. Many authors recommend to design for low or no damage, i.e. in order to avoid IA, given that this damage is cumulative.

It follows the Iribarren or Intermediate Damage (IR), where big holes can be seen in the outer armour layer and the stones of the inner armour layer are exposed to wave attack. Thirdly the Initiation of Destruction (IDe) is similar to the initiation of damage, but in the inner armour layer. Finally, Destruction (D) produces when the damage of the inner layer propagates and the secondary armour of filter layers are directly exposed to wave attack.

Damage criteria. Once identified these qualitative categories, the criterions to relate $N_{\mathrm{d}}$ with a specific damage category were defined (Table 2). This task was carried out after finishing the tests 1 to 3 , in order to take into account the specific conditions of the experimentation (slopes, crest width, stones shape, etc.). For the sake of comparison, these criterions are also expressed by two widely used non-dimensional magnitudes: (i) relative eroded area, $S$ (total eroded area relative to $D_{\mathrm{n} 50}{ }^{2}$ ); (ii) relative number of displaced units, $N_{\text {od }}$ (actual number of units displaced relative to a width of one nominal diameter). Regarding $N_{\text {od }}$, the expression $N_{\mathrm{d}} \approx 25 N_{\text {od }}$ can be used for both models. On the contrary, the relation is different for the relative eroded area, since it depends on the amour porosity. Assuming the armours settlements were negligible, this parameter could be estimated as $S \approx 2 N_{\text {od }}$ for cubic blocks and $S \approx 1.6 N_{\text {od }}$ for the rocks.

Figure 5 compares the criterions defined in Table 2 with those proposed by other authors. It is clear that most of the proposed values for $N_{\mathrm{d}}$ are fairly similar, especially for the lower degrees of damage. The most significant difference is found at the IA for cubes-armoured breakwaters (highlighted in the Figure). This can be explained because the references cited for cubes armours deal only with non-overtopped breakwaters used for harbour protection, which could be considered too restrictive in these cases. Indeed, when the breakwater is used for beach protection a higher degree of damage could be allowed, provided there are not very valuable facilities at the lee side.

\begin{tabular}{|c|c|c|c|c|c|c|}
\hline \multirow{2}{*}{$\begin{array}{l}\text { Damage } \\
\text { category }\end{array}$} & \multicolumn{3}{|c|}{ ROCKS } & \multicolumn{3}{|c|}{ CUBES } \\
\hline & $N_{d}$ & $N_{\text {od }}$ & $S$ & $N_{\mathrm{d}}$ & $N_{\text {od }}$ & $S$ \\
\hline IA & 12 & 0.5 & 0.85 & 7 & 0.25 & 0.5 \\
\hline IR & 37 & 1.5 & 2.5 & 13 & 0.5 & 1 \\
\hline IDe & 93 & 3.75 & 6 & 52 & 2 & 4 \\
\hline
\end{tabular}
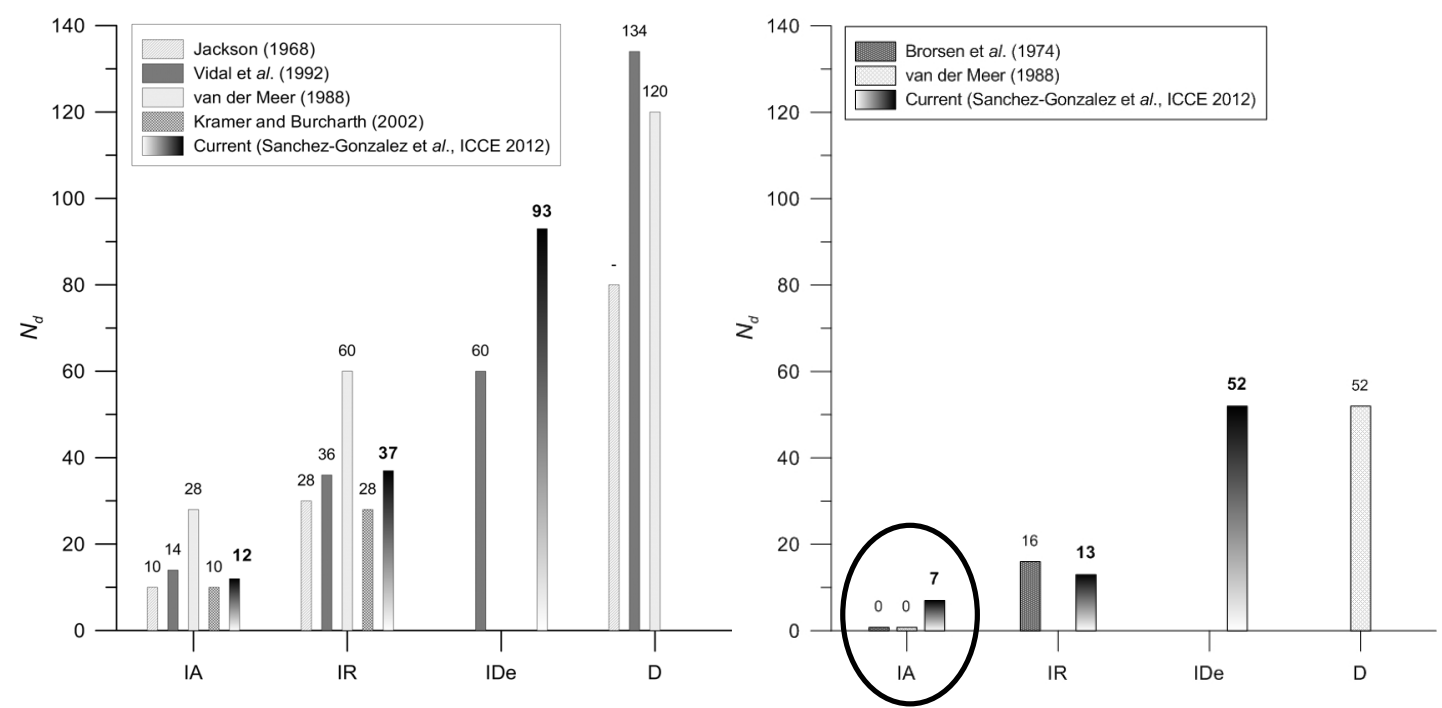

Figure 5. Damage criterions defined by the number of units displaced from the crest for rock-armoured breakwaters (left) and cubes-armoured breakwaters (right). 
Even so, the criterions proposed in Table 2 are more restrictive for the cubes armours in order to give a reasonably safe criterion, since the damage growth observed during the tests was much faster for the cubes once the first blocks started to move. Further details are given below.

\section{RESULTS}

\section{Damage description}

In general, damage in both models started at the front side and top of the crest. Regarding the first stages of damage, while most of the cubes fell down the rear slope without causing any damage on it, stones from the rock armour were displaced back and forward producing new displacements in the lower areas of the slopes. This contributed to increase the number of stones displaced, even though the damage category may not change.

Once the damage was initiated, the holes in the cubes armour layer increased close to the zones were the first movements had produced, being the damage concentrated (see Fig. 6). This led to a fast growth of the damage due to the lack of support of the cubes and possibly to the more intense flow produced around the damaged areas. On the other hand, stones were displaced from any part of the crest, producing dispersed and smaller damaged areas, although the total eroded area may be similar or even higher.

It is worthwhile to study the damage growth after IA on both models, considering its influence on the safety level of the damage criterions previously proposed in Table 2. Figure 7 shows the relative eroded area throughout Tests 5 to 8 , calculated from $N_{\mathrm{d}}$ as defined in the previous section. Wave action is represented by the stability number $N_{\mathrm{s} 50}=H_{50} / \Delta \mathrm{D}_{\mathrm{n} 50}$ (Vidal et al., 2006), where the wave parameter $H_{50}$ is the average wave height of the 50 highest waves that reached the structure, which is more or less proportional to the number of waves. According to Vidal et al. (2006) and van der Meer (1988), the results have been fitted to a curve of the type

$$
S=A \cdot\left(N_{s 50}-N_{s 50,0}\right)^{5}
$$

which seems to be a good estimation. The right panel shows how the cube-armoured layer erosion grew much faster once the IA was achieved, though in comparison with the rock armour it was produced for higher values of $N_{\mathrm{s} 50}\left(N_{\mathrm{s} 50, \mathrm{IA}, \text { cubes }}>N_{\mathrm{s} 50, \mathrm{IA}, \text { rocks }}\right)$. This justified the damage criteria exposed, more restrictive for cubes, otherwise the IDe wave height would be too close to the previous levels.

The final stages of damage observed in both models during this experiment were always close but under the destruction category (D). In most of the cases, almost the entire outer armour layer had been removed at the crest, while the inner layer remained unchanged, in part due to the increase in the freeboard. In summary, once the IDe was reached it was very difficult to get the Destruction, though the number of displacements $N_{\mathrm{d}}$ still continued rising.

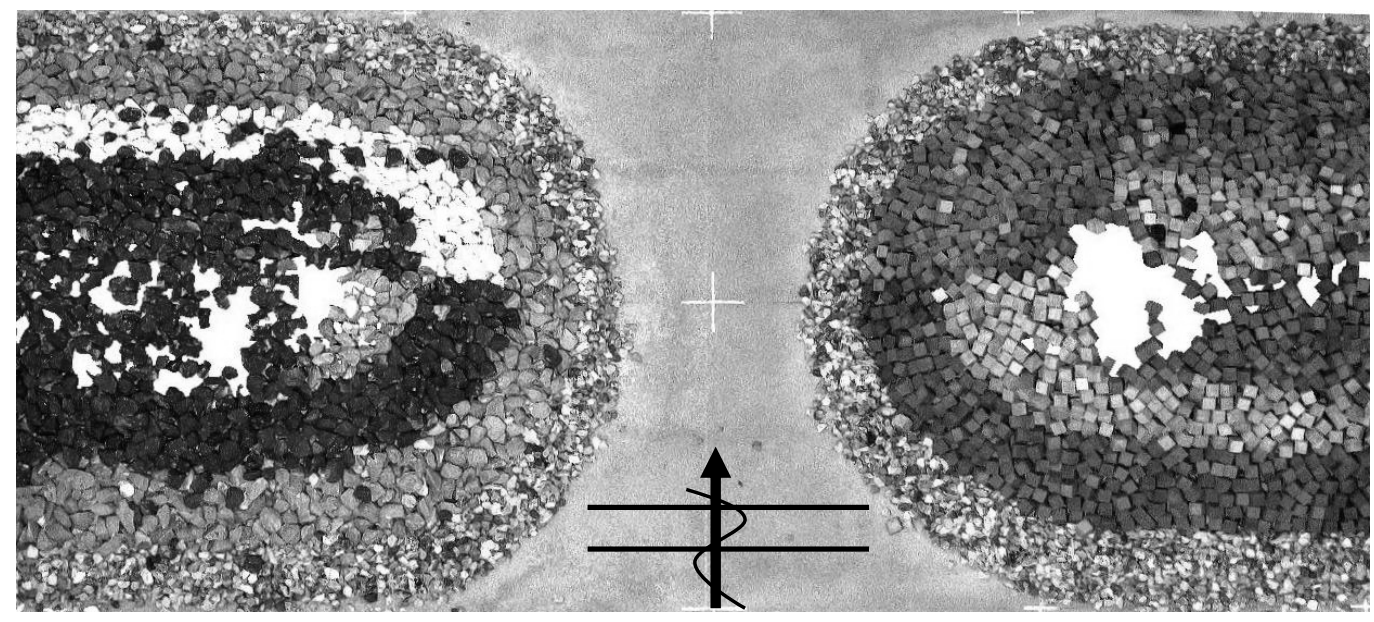

Figure 6. Damage location in both models, Test 5. Damage is considered IR for rock armour (left) and IDe for cube armour (right). Eroded areas are depicted in white. Note the stones of the rear slope of the rockarmoured breakwater were coloured in white, though this area had no erosion. 

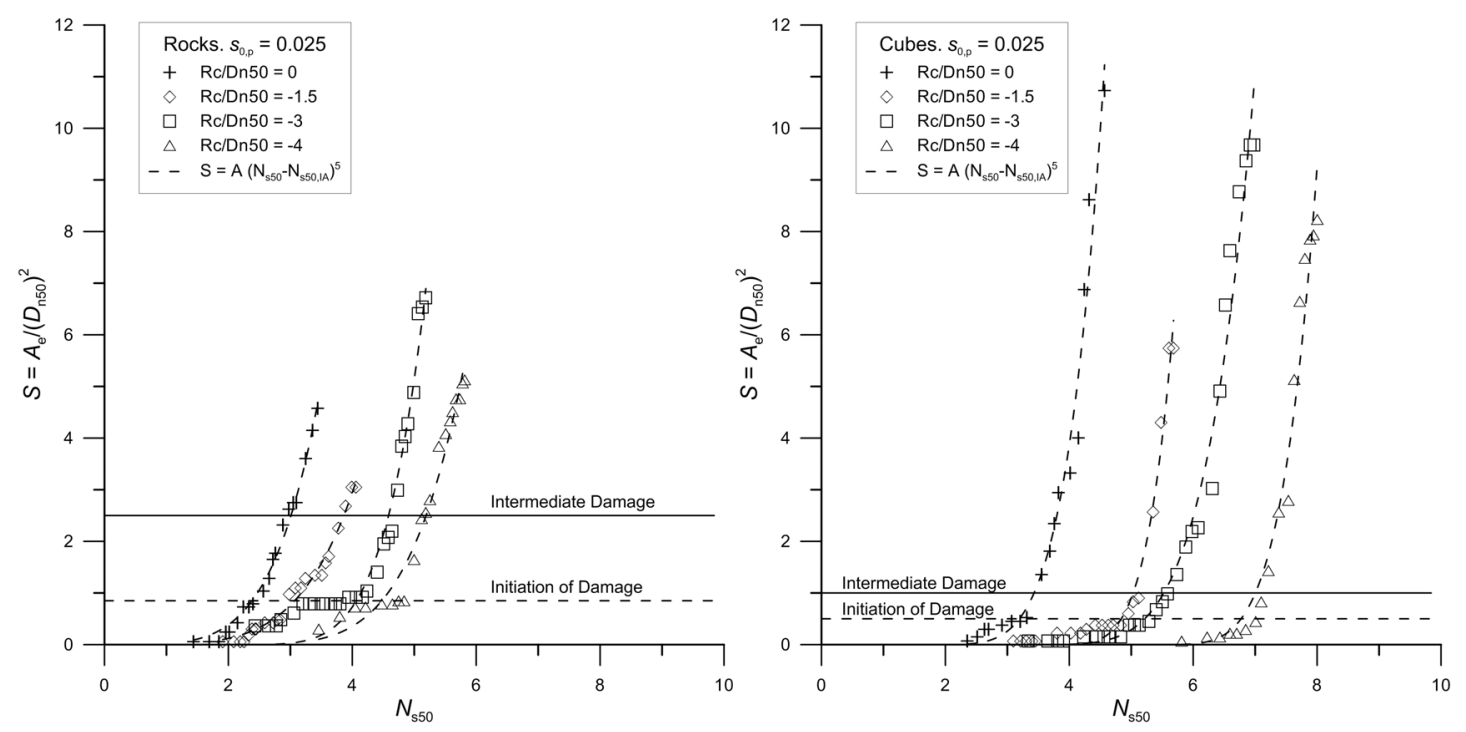

Figure 7. Damage growth during Tests 5 to 8 for rocks (left) and cubes (right) models.

\section{Stability}

Armour unit. Figures 8 and 9 present the stability results for both types of armours. Hereafter, the stability is represented by the stability number $N_{\mathrm{s}}=H_{\mathrm{s}} / \Delta D_{\mathrm{n} 50}$, where the wave parameter $H_{\mathrm{s}}$ is the incident significant wave height.

From these graphs, it can be seen that concrete-cubes armours were in general more stable than rock armours, with the exception of zero-freeboard conditions, where $N_{\mathrm{s}}$ is fairly similar. Furthermore, the stability number ratio grows slightly with the submergence, i.e. the ratio between stability numbers, $N_{\mathrm{s}, \text { Cubes }} / N_{\mathrm{s}, \text { Rock }}$ roughly ranges from 1.1 for zero freeboard to 1.4 for the maximum submergence (initiation of damage). If designing under the same wave conditions, this means that for submerged breakwaters the rock armour sizes should be greater than the cubes. Taking into account the different density of the stones and the concrete, this size ratio would be up to a $20 \%$ for the highest submergence.

As expected, the non-dimensional freeboard is the most important parameter both for the rocks and the cubes armours. Regarding the cubes armours, there is clearly a linear relation between the stability and $R_{\mathrm{c}} / D_{\mathrm{n} 50}$ for the three degrees of damage.

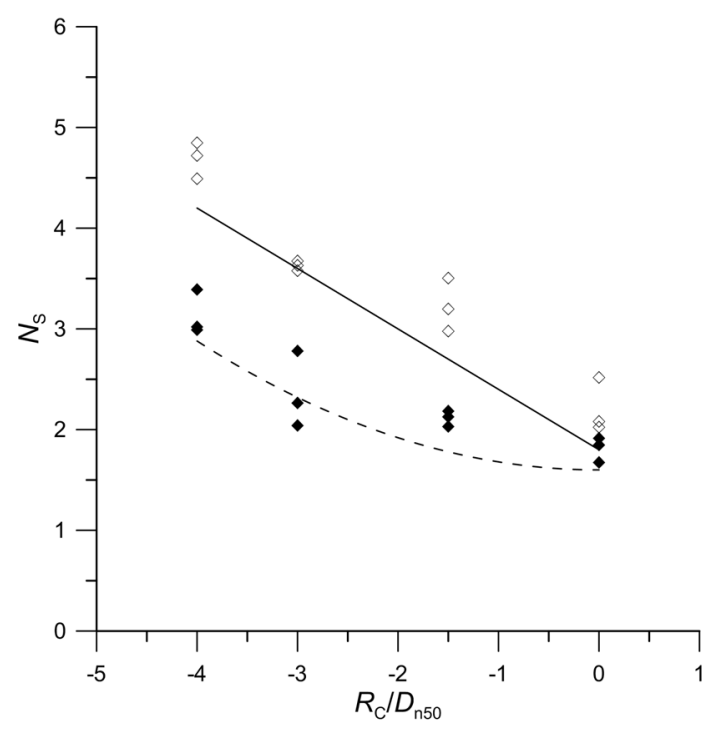

Figure 8. Stability results for the rock-armoured (solid) and cube-armoured (hollowed) models. Initiation of damage. Design curves of Eqs. (2) and (3) are also depicted in dashed (rock) and solid (cubes) lines. 

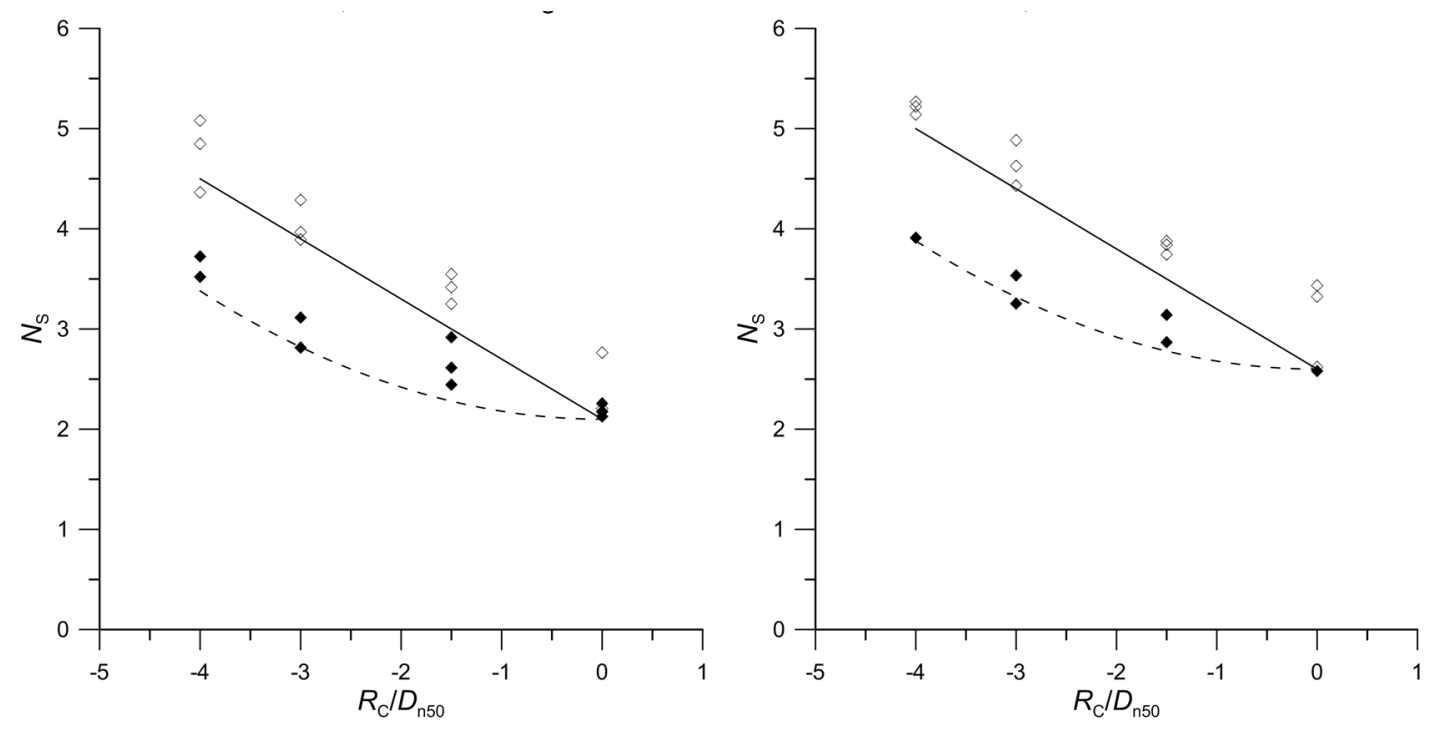

Figure 9. Stability results for the rock-armoured (solid) and cube-armoured (hollowed) models. Iribarren damage (IR, left) and initiation of destruction (IDe, right). Design curves of Eqs. (2) and (3) are also depicted in dashed (rock) and solid (cubes) lines.

Three parallel lines corresponding to the expressions of Eq. (2) have been depicted in Fig. 8 and 9 in order to design at the three degrees of damage:

$$
\left(N_{s}\right)_{\text {cubes }}=\left(N_{s, 0}\right)_{\text {cubes }}-0.6 \frac{R_{c}}{D_{n 50}}
$$

where $N_{\mathrm{s}, 0}$ depends on the damage category and is indicated in Table 3 .

\begin{tabular}{|ccc|}
\hline \multicolumn{3}{|l|}{$\begin{array}{l}\text { Table 3. Stability number } \\
\text { depending on the damage category. }\end{array}$} \\
\hline DAMAGE & ROCKS & CUBES \\
\hline IA & $1.3^{*}$ & 1.8 \\
IR & 2.1 & 2.1 \\
IDe & 2.6 & 2.6 \\
\hline
\end{tabular}

* The parabola sketched in Fig. 8 has $N_{\mathrm{s}, 0}=1.6$, which gives unsafe results for IA and $R_{\mathrm{c}} / D_{\mathrm{n} 50}=-3$. See Fig. 11 for further details.

On the other hand, the rock armour stability grows gently until very submerged conditions are reached. In this case, three parabolas have been depicted in Fig. 8 and 9, corresponding to the expressions of Eq. (3), with $N_{\mathrm{s}, 0}$ depending on the damage category as indicated above (see Table 3).

$$
\left(N_{s}\right)_{\text {rocks }}=\left(N_{s, 0}\right)_{\text {rocks }}-0.08 \cdot\left(\frac{R_{c}}{D_{n 50}}\right)^{2}
$$

These parabolas fit rather well the results obtained for the higher degrees of damage (Fig. 9) while under or overestimate the IA, depending on the non-dimensional freeboard (Fig. 8). This question is discussed in the next subsections, since it is related to the wave steepness effect.

Wave steepness. In order to study the wave steepness influence, Fig. 10 presents the initiation of damage in the tests for both types of armours, being the tested values of $s_{0, p}$ also indicated. As seen, in general the higher the steepness the higher the stability, with some exceptions for the lower submergences both for cube and rock armours. These differences are not significant, and it could be thought that the steepness does not actually have a strong effect compared with other variables.

Nevertheless, results from tests with the lower steepness showed a remarkable effect of the wave steepness, given that the stability number grows much more slowly for low submergences. Indeed, for initiation of damage and $s_{0, \mathrm{p}}=0.0175$, the value of $N_{\mathrm{s}}$ is almost constant for $-3 \leq R_{\mathrm{c}} / D_{\mathrm{n} 50} \leq 0$. This behaviour can be explained due to the higher drift flux transported in the longer waves. In order to give a safer design method, the expressions of Eq. (4) are proposed to design rock armours. 


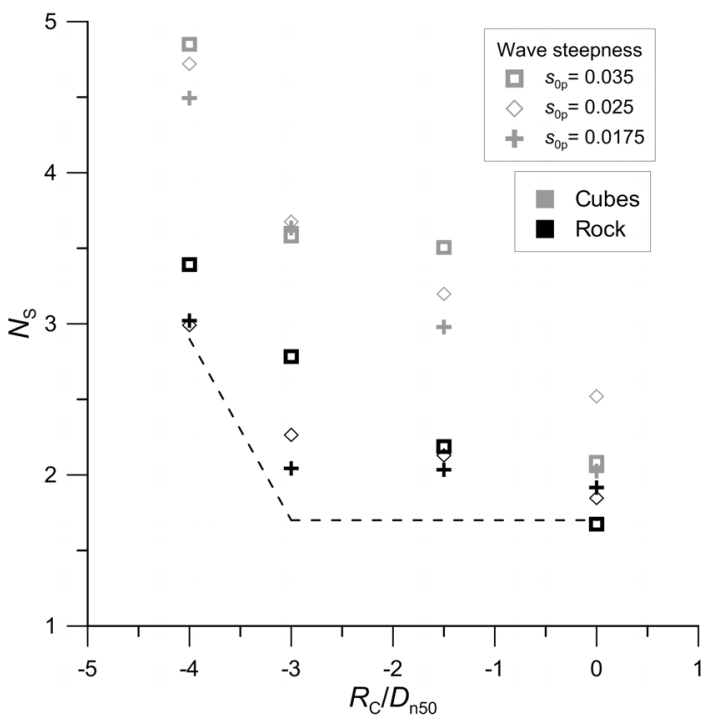

Figure 10. Stability results for the rock-armoured (black) and cube-armoured (grey) models, depending on the wave steepness. The dashed line represents the design curve given in Eq. (4).

$$
\begin{aligned}
& N_{s, I A}=-1.9-1.2 \frac{R_{c}}{D_{n 50}} \text { for }-4 \leq \frac{R_{c}}{D_{n 50}}<-3 \\
& N_{s, I A}=1.7 \text { for } \frac{R_{c}}{D_{n 50}} \geq-3
\end{aligned}
$$

Previous researches. Figure 11 compares CEDEX-2012 results with those from previous similar investigations on submerged structures and LCS (rock armoured rubble-mound in all cases). Vidal et al. (1992) tested a 3-D model with random head-on waves at the National Reseach Council in Canada, with zero freeboard and one submerged condition. Kramer and Burcharth (2002) tested a 3-D model under random 3-D waves at Aalborg University, under the framework of the DELOS Project. In both cases minor differences are expected with the results obtained at CEDEX, since the three tests dealt with quite similar structures with similar damage criterions (Fig. 5).

Results show similar trends for the three datasets, being the major differences for $R_{\mathrm{c}} / D_{\mathrm{n} 50}=0$, where the previous tests gave less stable results. This has been taken into account in Table 3 in order to give a safe design method for IA in rock armours $\left(N_{\mathrm{s}, 0}\right.$ corresponds with the parabola sketched below).

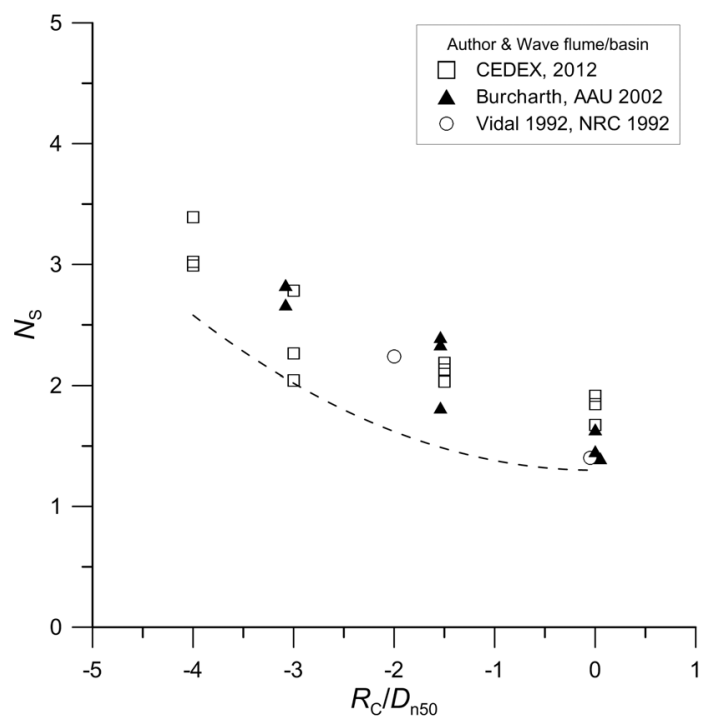

Figure 11. Comparison between results from new tests carried out at CEDEX and those from Vidal et al. (1992) and Kramer and Burcharth (2002). Initiation of damage in the rock-armoured breakwater. 


\section{CONCLUSIONS}

A new set of physical model tests is presented to contribute to the state of the art mainly due to the test of concrete-cube armours and the increased submergence, but also with a higher model scale. Two 3-D models armoured with two layers of rocks or precast concrete cubes were tested in a wave flume in the Laboratory for Maritime Experimentation, at the Centre for Harbour and Coastal Studies of CEDEX (Spain).

This design was set in order to reach the initiation of destruction (Losada et al., 1986) or at least the intermediate damage for the most submerged structure. Damage criterions are discussed and proposed for both types of armour. Regarding the damage criterions for rock armours, our proposal is quite similar to those from previous researches dealing with rubble-mound submerged breakwaters. On the other hand, for cube armours it is proposed to reduce the damage thresholds in order to increase the safety, taking into account the different damage growth observed between rock and cubes-armours. This proposal, however, allows some degree of damage before considering the initiation of damage, in contrast with other previous proposals for harbour breakwaters.

Concerning the stability, the main conclusion is that the cubes are in general more stable than the rocks. While both armours have similar stability number for zero freeboard, the cubes have much higher stability number for submerged conditions. Furthermore, $N_{\mathrm{s}}$ for cubes grows faster with the submergence for the tested conditions. For the same wave height the rock armour unit size should be always greater than the cube, ranging from 5\% higher for null freeboard and up to a $20 \%$ higher for the highest submergence.

As expected, the non-dimensional freeboard is the most important parameter both for the rocks and the cubes armours, though the behaviours are different depending on the armour type. Though in principle it could be thought that the steepness does not influence the stability, it seems that in the rock armours the lower wave steepness have a remarkable effect, since the value of $N_{\mathrm{s}}$ is almost constant for $-3 \leq R_{\mathrm{c}} / D_{\mathrm{n} 50} \leq 0$. In order to give a design method for both armour units and three damage categories, two expressions have been proposed in Eqs. (2) and (3) and the parameters indicated in Table 3.

\section{ACKNOWLEDGEMENTS}

This study was financed by the Directorate General for the Sustainability of the Coast and the Sea, of the Government of Spain. The work was motivated by a working group of the Spanish Section of the PIANC, committed to elaborate a set of recommendations regarding the design of submerged breakwaters for beach protection. The WG is composed of members of the government, scientific staff, consulting and construction companies and has been working since 2009 in the guidelines, which are almost finished. The authors gratefully acknowledge to all the WG members for their support and hard work developed during this time.

\section{REFERENCES}

Ahrens, J.P. 1989. Stability of reef breakwaters, Journal of Waterways, Ports, Coastal and Ocean Engineering, 115 (2), 221-234.

Brorsen, M., Burcharth, H. F., and Larsen, T. 1974. Stability of Dolos Slopes. Proceedings of the $14^{\text {th }}$ International Conference on Coastal Engineering, ASCE, 1691-1701.

Burcharth, H.F., Kramer, M., Lamberti, A., Zanuttigh, B. 2006. Structural stability of detached low crested breakwaters, Coastal Engineering, 53 (4), 381-394.

Burchart, H.F., Hawkings, S.J., Zanuttigh, B., Lamberti, A., 2007. Environmental design guidelines for low crested coastal structures. Elsevier, London, $400 \mathrm{pp}$.

Givler, L.D. and Sørensen, R.M., 1986. An Investigation of the stability of submerged homogeneous rubble-mound structures under wave attack, Lehigh University, H.R. IMBT Hydraulics Report \#IHL-110-86.

Jackson, R. A. 1968. Design of Cover Layers for Rubble-Mound Breakwaters Subjected to Nonbreaking Waves. Research Report No. 2-11, U.S. Army Engineer Waterways Experiment Station, Vicksburg, MS.

Kramer, M. and Burcharth, H.F. 2002. Wave basin experiment final form, 3-D stability tests at Aalborg University. Report of DELOS EVK-CT-2000-0004/.

Losada, M.A., Desire, J.M., Alejo, L.M., 1986. Stability of blocks as breakwaters armour units. Journal of Structural Engineering, 112 (1), 2392 - 2401. 
Mansard D.P.D. and Funke, E.R. 1980. The measurement of incident and reflected spectra using a least squares method. Proceedings of the $17^{\text {th }}$ International Conference on Coastal Engineering, ASCE, 154-172.

van der Meer, J.W. 1988. Rock slopes and gravel beaches under wave attack. Delf Hydraulics Communication N. 396, Delft.

van der Meer, J.W. and Daemen, I.F.R. 1994. Stability and wave transmission at low crested rubble mound structures. Journal of Waterways, Ports, Coastal and Ocean Engineering, 120 (1), 1-19.

Vidal, C., Losada, M.A., Medina, R., Mansard, E.P.D. , Gomez-Pina, G. 1992. A universal analysis for the stability of both low-crested and submerged breakwaters, Proceedings of $23^{\text {rd }}$ International Conference on Coastal Engineering, ASCE, 1679-1692.

Vidal, C., Medina, R., Martín, F.L. 2000. A methodology to assess the armour stability of low-crested and submerged rubble-mound breakwaters. Coastal Structures, $721-725$.

Vidal, C., Medina, R., Lomónaco, P. 2006. Wave height parameter for damage description of rubblemound breakwaters. Coastal Engineering, 53(6), 711 - 722. 